\title{
Profil Kompetensi Pedagogik Guru Sekolah Dasar
}

\section{Kinanty $^{1 *}$, Zaka Hadikusuma Ramadan ${ }^{2}$}

1,2,3 Program Studi Pendidikan Guru Sekolah Dasar, Universitas Islam Riau, Riau, Indonesia

\section{ARTICLE INFO}

Article history:

Received October 19, 2021

Revised October 20, 2021

Accepted November 29, 2021

Available online December 25, 2021

Kata Kunci:

Kompetensi Pedagogic, Guru

Sekolah Dasar

Keywords:

Pedagogic Competencies,

Elementary School Teachers

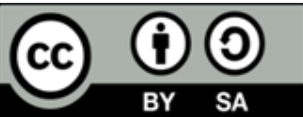

This is an open access article under the CC BY-SA license.

Copyright (ㄷ) 2021 by Author. Published by Universitas Pendidikan Ganesha.

\begin{abstract}
A B S T R A K
Faktor yang mempengaruhi tercapainnya tujuan pembelajaran dan pendidikan di sekolah adalah kompetensi yang dimiliki oleh gurusalah satu kompetensi yang hasrus dikuasi guru dalam proses pembelajaran adalah kompetensi pedagofik. Tujuan penelitian ini adalah untuk mengetahui profil kompetensi pedagogik guru sekolah dasar. Penelitian ini menggunakan metode deskriptif kuantitatif. Subjek penelitiannya adalah guru yang mengajar di sekolah dasar. Data yang digunakan merupakan data yang dikumpulkan melalui observasi, angket dan studi dokumentasi. Analisis data menggunakan rata-rata dan presentase skor. Hasil penelitian ini menunjukkan kemampuan kompetensi pedagogik pada indikator memahami peserta didik secaraa mendalam $(83,9 \%)$ merancang pembelajaran termasuk memahami landasan pendidikan untuk kepentingan pembelajaran $(83 \%)$ melaksanakan pembelajaran $(74 \%)$ merancang dan melaksanakan evaluasi pembelajaran $(88 \%)$ mengembangkan kompetensi peserta didik untuk mengaktualisasikan berbagai kompetensinya $(85 \%)$ secara keseluruhan kompetensi pedagogik di se kecamatan Ukui adalah (82\%) dengan kategori sangat kuat. Jadi dapat disimpulkan guru yang berada di kecamatan ukui telah memiliki kompetensi pedagogik yang sangat kuat sehingga dapat memberikan kontribusi yang signifikan dalam pelaksanaan pembelajaran. Implikasi penelitian ini adalah dapat memberikan kesadaran pada guru akan pentingnya penguasaan kompetensi pedagogik.
\end{abstract}

\section{A B S T R A C T}

Factors that influence the achievement of learning and educational goals in schools are competencies possessed by teachers. One of the competencies that teachers must master in the learning process is pedagogic competence. This study aims to determine the profile of the pedagogic competence of elementary school teachers. This study uses a quantitative descriptive method. The research subjects are teachers who teach in elementary schools. The data used are data collected through observation, questionnaires, and documentation studies. Analysis of the data using the average and percentage scores. The results of this study indicate the ability of pedagogic competence on the indicators of understanding students in-depth (83.9\%) designing learning including understanding the educational foundation for learning purposes (83\%) implementing learning (74\%) designing and implementing learning evaluations (88\%) developing competencies students to actualize their various competencies (85\%) overall pedagogic competence in all Ukui sub-districts is (82\%) with a very strong category. So it can be concluded that teachers have very strong pedagogic competence so that they can make a significant contribution to the implementation of learning. This research implies that it can provide awareness to teachers about the importance of mastering pedagogic competencies.

\section{PENDAHULUAN}

Guru merupakan komponen penting dalam proses pendidikan (Putri, Mudzanatun, \& Putri, 2020; Sakti, Hairunisya, \& Sujai, 2019) Guru adalah salah satu profesi yang mulai dan terhormat yang memegang kendali dalam mencetak peradaban dan kemajuan suatu generasi (Akbar, 2021). Guru sebagai pendidik yang berkualitas juga akan menghasilkan peserta didik yang berkualitas (Asmahasanah, Sa'diyah, \& Ibdalsyah, 2018; Indriani, 2015). Kehandalan kemampuan guru dalam mengajar dan mendidik dibidangnya akan memaksimalkan ketercapaian target dan sasaran pendidikan di sekolah. Demi mewujudkan hal tersebut, maka harus diawali dengan guru memiliki kompetensi yang baik dalam 
melaksanakan profesinya (Karom, Ruhimat, \& Darmawan, 2014). Kompetensi merupakan perangkat pengetahuan, keterampilan, dan perilaku yang harus dimiliki, dikuasai dan di aktualisasikan oleh guru dalam melaksanakan tugas keprofesionalan (Sutisna \& Widodo, 2020; Triyusmidarti \& Fauziyah Harahap, 2017). Kompetensi guru merupakan kemampuan seseorang guru dalam melaksanakan kewajibankewajibannya secara tanggungjawab dan layak (Sulfemi \& Yuliana, 2019). Namun yang terjadi di lapangan kompetensi guru saat ini masih beragam. Salah satu krisis pendidikan di Indonesia guru belum mampu menunjukkan kinerja yang memadai (Sumiarsi, 2015). Guru dalam mengelola pembelajaran perlu perhatian, karena pendidikan di Indonesia dinyatakan kurang berhasil dinilai dari aspek pedagogis (Afriyani, Suklani, \& Ridwan, 2017; Arsyad \& Sulfemi, 2019). Hal ini terlihat pada fenomena-fenomena yang terjadi pada guru antara lain dalam proses pembelajaran guru menganggap semua peserta didik yang dibinanya memiliki karakteristik yang sama, kurangnya kreativitas guru dalam menetapkan berbagai pendekatan, strategi, metode dan teknik dalam belajar, Dalam proses pembelajaran guru hanya bersifat monoton atau hanya memperhatikan aspek kognitifnya saja dan kurangnya pembinaan perilaku positif (Nur, 2014; Pertiwi \& Renda, 2020). Hal ini dibuktikan dengan masih seringnya ditemukan guruguru yang masih belum maksimal bahkan belum mampu dalam merencanakan proses pembelajaran melaksanakan proses pembelajaran serta melakukan evaluasi terhadap proses pembelajaran dan hasil belajar (Saputri \& Purwadi, 2017; Wahyuni \& Berliani, 2018) Berdasarkan hal tersebut dapat dikatakan bahwa tenaga pendidik belum memenuhi kualifikasi sebagai tenaga pendidik yang berkompeten dalam pengelolaan pembelajaran (Darimi, 2015). Oleh karena itu dalam proses pembelajaran guru harus menguasai kompetensi yang dibutuhkan untuk menghasilkan sebuah pembelajaran yang berkualitas (Dody, 2016). Kompetensi yang harus dimiliki oleh guru yaitu kompetensi pedagogis, kepribadian, sosial, dan professional (Dahlan, Iriawan \& Hamdan., 2016; Gani, Nur, M., Mallongi, \& Rusjdin, 2018; Jatiningsih, Maya Mustika Kartika Sari, Habibah, Setyowati, Yani, \& Adi, 2018). Dari ke empat kompetensi guru tersebut kompetensi pedagogik guru menempati tempat yang paling penting dalam pendidikan pada umumnya serta dalam pelaksanaan pembelajaran karena guru memegang peranan dalam proses tersebut, dimana proses pembelajaran merupakan inti dari proses pendidikan secara keseluruhan yang melibatkan aspek kompetensi (Hasli, Sappaile, \& Pristiwaluyo, 2015).

Kompetensi pedagogik adalah kemampuan guru dalam mengelola pembelajaran (Sumiarsi, 2015; Syarifuddin, 2020). Kompetensi Pedagogik mencakup pengetahuan yang baik, luas dan mendalam tentang subjek atau materi pembelajaran. Seorang guru pedagogis harus menunjukkan kemampuan yang baik dalam menggunakan dan menerapkan pengetahuan baik bersifat praktis. Selain itu, kompetensi pedagogik diartikan sebagai seperangkat pengetahuan, keterampilan, dan sikap yang dimiliki oleh guru dalam membimbing siswa dalam proses pembelajaran agar mencapai kedewasaan dan kemandirian (Karom et al., 2014; Khofiatun, Akbar, \& Ramli, 2016; Umi, Nopriansyah, \& Purnama, 2019). Pedagogik adalah ilmu tentang pendidikan anak yang ruang lingkupnya terbatas antar pendidik dengan peserta didik . Secara rinci masing-masing elemen kompetensi pedagogik dapat dijabarkan menjadi subkompetensi dan indikator esensial yaitu (1) memahami peserta didik (2) merancang pembelajaran (3) melaksanakan pembelajaran (4) melaksanakan dan merancang pembelajaran (5) mengembangkan peserta didik untuk mengaktualisasikan berbagai potensi yang dimilikinya (Widyaningrum, Sondari, \& Mulyati, 2019). Dalam proses pembelajaran, seorang guru perlu merancang terlebih dahulu program pembelajarannya, artinya seorang guru dalam mengajar perlu merancang pengorganisasian bahan pelajaran yang jelas merancang pengelolaan kelas, merancang strategi pembelajaran, merancang media pembelajaran serta merancang evaluasi pembelajaran siswa. Untuk mengatasi masalah tersebut diperlukan peningkatan tenaga pendidik yang berkompeten sehingga tujuan yang diharapkan tercapai. Salah satu cara untuk meningkatkan kualitas pendidikan adalah dengan memperkuat kompetensi guru sehingga seluruh kompetensinya dapat dimaksimalkan. Selain itu pemanfaatan teknologi dan komunikasi juga dapat meningkatkan kompetensi pedagogik. Padahal kompetensi pedagogik sangat diperlukan untuk memperbaiki proses dan kualitas pengajaran.

Penelitian ini relevan dengan beberapa penelitian sebelumnya yaitu 1) penelitian oleh (Oetpah, 2019) yang menunjukkan bahwa kontribusi kompetensi pedagogik dan kompetensi profesional guru biologi sangat berpengaruh terhadap prestasi belajar biologi siswa, 2) penelitian oleh (Khofiatun et al., 2016) yang menunjukkan . peran kompetensi pedagogik guru dalam proses pembelajaran berpengaruh terhadap hasil pembelajaran tematatik 3) penelitian oleh (Tyagita \& Iriani, 2018; Yulyani, Kazumaretha, Arisanti, Y., Fitria, \& Desyandri, 2020) yang menunjukkan bahwa kompetensi pedagogic berperan sangat penting bagi guru bagi keberhasilan guru dalam pembelajaran tematik di kelasnya. Adapun yang membedakan antara penelitian ini dengan penelitian sebelumnya yakni pada tempat pelaksanaan penelitian serta tujuan yang ingin dicapai. Penelitian ini berfokus pada profil kompetensi pedagogic yang ada di sekolah dasar. Tujuan yang hendak dicapai melalui penelitian ini adalah untuk mengetahui profil kompetensi pedagogik guru sekolah dasar. di kecamatan Ukui. 


\section{METODE}

Penelitian ini menggunakan metode penelitian deskriptif kuantitatif dengan menggunakan angka kemudian dijelaskan menggunakan kalimat. Penelitian dilaksanakan di seluruh sekolah dasar negeri di kecamatan Ukui kabupaten Pelalawan pada tanggal 23-28 Agustus 2021. Penelitian ini bertujuan untuk menggambarkan bagaimana kompetensi pedagogik guru sekolah dasar se kecamatan Ukui. Populasi penelitian ini adalah seluruh sekolah dasar negeri di kecamatan Ukui kabupaten Pelalawan sebanyak 10 sekolah. Subjek penelitian adalah guru yang mengajar di sekolah dasar se kecamatan Ukui. Dalam penelitian ini penulis mengumpulkan data dengan beberapa teknik seperti angket dan dokumentasi. Kisikisi dari angket yang digunakan meliputi beberapa indikator yaitu: 1. Memahami peserta didik secara mendalam, 2) Merancang pembelajaran termasuk memahami landasan pendidikan untuk kepentingan pembelajaran, 3) Melaksanakan pembelajaran, 4) Merancang dan melaksanakan evaluasi pembelajaran, dan 5 Mengembangkan kompetensi peserta didik untuk mengaktualisasikan berbagai kompetensinya. Data yang telah terkumpul dianalisis menggunakan analisis deskriptif kualitatif dan kuantitatif.

\section{HASIL DAN PEMBAHASAN}

Hasil

Dalam pembahasan hasil penelitian ini akan di upayakan untuk menginterpretasikan hasil temuan penelitian di lapangan yang telah diperoleh. Berdasarkan data yang diperoleh dari hasil penelitian guru sekolah dasar di se kecamatan Ukui kabupaten Pelalawan, untuk melihat aspek-aspek dalam kompetensi pedagogik guru tersebut secara keseluruhan dengan deskripsi skor dikategorikan menjadi sangat lemah, lemah,cukup, kuat dan sangat kuat. Hasil penelitian mengenai kompetensi pedagogik guru yang diukur berdasarkan lima indikator yaitu memahami peserta didik secara mendalam dengan jumlah 83,9\% tergolong ke dalam kategori sangat kuat, Merancang pembelajaran termasuk memahami landasan pendidikan untuk kepentingan pembelajaran dengan jumlah $83 \%$ tergolong ke dalam kategori sangat kuat, melaksanakan pembelajaran dengan jumlaah $74 \%$ tergolong ke dalam kategori kuat, merancang dan melaksanakan evaluasi pembelajaran dengan jumlah 88\% tergolong ke dalam kategori sangat kuat, dan mengembangkan kompetensi peserta didik untuk mengaktualisasikan berbagai kompetensinya dengan jumlah $85 \%$ tergolong ke dalam kategori saangat kuat. Berdasarkan data yang diperoleh peneliti di lapangan dapat dijabarkan bahwa untuk skor tertinggi berada pada indikator Mengembangkan kompetensi peserta didik untuk mengaktualisasikan berbagai kompetensinya yaitu sebesar $85 \%$ dan skor rata-rata terendah adalah pada indikator melaksanakan pembelajaran yaitu sebesar 74\%. Berdasarkan hasil penelitian diketahui bahwa hasil skor pernyataan mengenai kompetensi pedagogik guru Secara keseluruhan adalah sebesar 82\%. Dapat di simpulkan bahwa kompetensi pedagogik guru sekolah dasar di kecamatan Ukui kabupaten Pelalawan dipersepsikan sangat kuat.

\section{Pembahasan}

Kompetensi pedagogik merupakan hal penting yang harus dikuasai oleh para guru, karena kompetensi pedagogik merupakan syarat utama dalam menyelenggarakan pembelajaran yang efektif bagi siswa untuk tercapainya harapan proses pendidikan. Dengan demikian guru berperan di dalam proes kegiatan pembelajaran agar berjalan secara optimal (Sari, 2018). Kemampuan pedagogik seorang guru mengharuskan guru untuk mempersiapakan berbagai pembelajaran sebelum mengajar (Nuralan, 2020). Temuan pertama guru memahami pesera didik secara mendalam, berdsarkan hasil penelitian menunjukkan bahwa guru-guru di sekolah dasar se kecamatan ukui mampu memahami peserta didik secara mendalam. Dalam kaitannya dengan kualitas pembelajaran, jika guru dapat memahami peserta didik dengan memanfaatkan prinsip prinsip perkembangan kognitif peserta didik, maka peserta didik dapat terpenuhi rasa ingin tahunya, peserta didik memiliki keberanian berpendapat dan kemampuan menyelesaikan masalah, peserta didik dapat lebih nyaman dalam kegiatan belajarnya (Abrar, 2020). Guru perlu memahami peserta didik melalui karakteristik peserta didik yang berkaitan dengan aspek intelektual, emosional, moral dan latar belakang peserta didik sehingga tujuan pembelajaran tercapai sesuai yang diharapkan (Muhammad Ridwan Kalu \& Mahpudz, 2016).

Temuan kedua guru merancang pembelajaran termasuk memahami landasan pendidikaan untuk kepentingan pembelajaran merupakan aspek penting dalam kompetensi pedagogik. Di sini guru harus menguasai materi pembelajaran, guru perlu terampil merancang dan melaksanakan strategi pembelajaran. Dapat dilihat rata-rata skor kompetensi pedagogik guru sekolah dasar di kecamatan Ukui kabupaten Pelalawan dalam Merancang Pembelajaran Termasuk Memahami Landasan Pendidikan Untuk Kepentingan Pembelajaran menunjukkan pada angka 83\% berada pada kriteria sangat kuat. Hal ini menunjukkan bahwa guru-guru di sekolah dasar se kecamatan ukui mampu merancang pembelajaran termasuk memahami landasan pendidikan untuk kepentingan pembelajaran (Jatiningsih et al., 2018; 
Sukriadi \& Arif, 2021). Temuan ketiga yaitu melaksanakan pembelajaran. Dapat dilihat rata-rata skor kompetensi pedagogik guru sekolah di kecamatan Ukui kabupaten Pelalawan dalam melaksanakan pembelajaran menunjukkan pada angka 74\% berada pada kriteria kuat. Hal ini menunjukkan bahwa guruguru di sekolah dasar se kecamatan Ukui mampu melaksanakan pembelajaran dikelas. Temuan keempat yaitu merancang dan melaksanakan evaluasi pembelajaran. Dapat dilihat rata-rata skor kompetensi pedagogik guru sekolah dasar di kecamatan Ukui kabupaten Pelalawan dalam merancang dan melaksanakan evaluasi pembelajaran menunjukkan pada angka $88 \%$ berada pada kriteria sangat kuat. Hal ini menunjukkan bahwa guru-guru di sekolah dasar kecamatan Ukui mampu merancang dan melaksanakan evaluasi pembelajaran.

Temuan kelima adalah mengembangkan kompetensi peserta didik untuk mengaktualisasikan berbagai kompetensinya. Dalam hal ini guru kelas mengembangkan peserta didik untuk mengaktualisasikan berbagai potensi peserta didik yaitu dengan memberikan fasilitas seluas-luasnya kepada peserta didik (Riwanti \& Hidyati, 2019; Stephani, 2017). Dalam hal ini sangat mensupport setiap guru yang menemukan bakat-bakat tertentu dari peserta didik dengan memberikan fasilitas yang diperlukan. Dapat dilihat rata-rata skor kompetensi pedagogik guru sekolah dasar di kecamatan Ukui kabupaten Pelalawan dalam mengembangkan kompetensi peserta didik untuk mengaktualisasikan berbagai kompetensinya menunjukkan pada angka $85 \%$ berada pada kriteria sangat kuat. Hal ini menunjukkan bahwa guru-guru di sekolah dasar se kecamatan ukui mampu mengembangkan kompetensi peserta didik untuk mengaktualisasikan berbagai kompetensinya. Berdasarkan hasil temuan pada penelitian ini, keterampilan yang diterapkan oleh guru dipengaruhi oleh kompetensi pedagogik yang dimiliki (Afandi \& Wahyuningsih, 2018; Sutisna \& Widodo, 2020). Kompetensi pedagogik memberikan kontribusi yang signifikan dengan keterampilan mengajar pada guru dalam pelaksanaan pembelajaran. Kompetensi merupakan kemampuan seseorang untuk melaksanakan tugas dan tanggung jawab, sedangkan pedagogik merupakan kemampuan guru dalam mengelola pembelajaran dan melakukan komunikasi yang baik dengan siswa (Karom et al., 2014; Khofiatun et al., 2016; Umi et al., 2019). Sehingga dapat dikatakan bahwa kompetensi pedagogik merupakan seperangkat pengetahuan, keterampilan, dan sikap yang dimiliki oleh guru dalam melakukan bimbingan kepada siswa melalui proses pembelajaran yang mendidik dan komunikatif. Kompetensi pedagogik ini erat kaitannya dengan proses pembelajaran.

Penelitian ini didukung beberapa penelitian sebelumnya yang relevan dengan penelitian ini seperti: (1) penelitian yang dilakukan oleh (Karom et al., 2014) yang memperoleh hasil bahwa kompetensi pedagogik guru dalam menerapkan pembelajaran kooperatif berbantuan media presentasi dapat mempengaruhi hasil belajar hasil belajar matematika; (2) penelitian yang dilakukan oleh (Akbar, 2021; Maiza \& Nurhafizah, 2019) menunjukkan bahwa yang profesionalisme guru dapat ditingkatkan dengan pelatihan keprofesian. 3) penelitian oleh (Antari \& Sujana, 2021) kompetensi pedagogik memberikan kontribusi yang signifikan kepada guru dalam pelaksanaan pembelajaran. Implikasi penelitian ini adalah dapat memberikan gambaran bagaimana kompetensi yang dimiliki oleh guru sangat mempengaruhi keberhasilan proses pembelajaran. Oleh karena itu guru harus selalu haus akan ilmu agar dapat meningkatkan kompetensi yang dimiliki dengan mengikuti kegiatan pelatihan prfesi.

\section{SIMPULAN}

Profil kompetensi pedagogi guru dan sekolah dasar kecamatan Ukui sangat kuat hal ini dilihat dari, indikator dari kompetensi pedagogik mulai dari memahami pesera didik secara mendalam, merancang pembelajaran, melaksanakan pembelajaran, merancang dan melaksanakan evaluasi pembelajaran, serta mengembangkan kompetensi peserta didik untuk mengaktualisasikan berbagai kompetensinya sudah dilaksanakan dengan sangat baik. Hasil dari penelitian ini dapat dijadikan sebagai bahan refleksi bagi guru untuk senantiasa selalu meningkatkan kualitas dalam mendidik, referensi dalam pengambilan keputusan bagi kepala sekolah dan membantu peneliti lain dalam mengembangkan ilmu pengetahuan. Implikasi penelitian ini adalah dapat memberikan sumbangan pemikiran dan dapat memberikan kesadaran akan pentingnya penguasaan kompetensi pedagogik bagi guru dalam pelaksanaan pembelajaran.

\section{DAFTAR PUSTAKA}

Abrar, A. M. (2020). Kompetensi Pedagogik Guru Pendidikan Agama Islam Dalam Meningkatkan Interaksi Pembelajaran Peserta Didik Sd Integral Rahmatullah Tolitoli. Al-Qalam: Jurnal Kajian Islam \& Pendidikan, 12(1), 33. https://doi.org/10.47435/al-qalam.v2i1.367.

Afandi, M., \& Wahyuningsih, S. (2018). Analisis Kompetensi Pedagogik Guru Sd Di UPTD Pendidikan Banyumanik Kota Semarang. Elementary, 6(1). https://doi.org/10.21043/elementary.v6i1.3997. 
Afriyani, E., Suklani, S., \& Ridwan, W. A. (2017). Pengaruh Kompetensi Pedagogik Guru terhadap Prestasi Belajar Siswa Madrasah Aliyah (MA) An-Nur Kota Cirebon (Studi pada Pembelajaran Aqidah Akhlak). Jurnal Al-Tarbawi Al-Haditsah, 2(1). https://doi.org/10.24235/tarbawi.v2i1.2029.

Akbar, A. (2021). Pentingnya Kompetensi Pedagogik Guru. JPG: Jurnal Pendidikan Guru, 2(1), 23-30. https://doi.org/10.32832/jpg.v2i1.4099.

Antari, N. K. Y., \& Sujana, I. W. (2021). Kontribusi Kompetensi Pedagogik dan Profesional dengan Keterampilan Penerapan Gestur Guru dalam Pelaksanaan Pembelajaran. Mimbar PGSD Undiksha, 9(1), 93-103. https://doi.org/10.23887/jjpgsd.v9i1.32017.

Arsyad, \& Sulfemi, W. B. (2019). Pengaruh Kelompok Kerja Guru (KKG) Terhadap Peningkatan Kompetensi Pedagogik dan Kemampuan Menulis Karya Ilmiah. Jurnal Pendidikan Dasar Indonesia, 4(2), 53-58. https://doi.org/10.26737/jpdi.v4i2.1522.

Asmahasanah, S., Sa'diyah, M., \& Ibdalsyah. (2018). Analisis Keterampilan Mengajar Guru Dan Penanaman Nilai Positif Melalui Pemanfaatan Kebun Sekolah. Sekolah Dasar: Kajian Teori Dan Praktik Pendidikan, 27(2), 167-173. https://doi.org/10.17977/um009v27i22018p167.

Dahlan, Iriawan, H., \& Hamdan. (2016). Pengaruh Kompetensi Manajerial Kepala Sekolah Terhadap Kompetensi Sosial Guru Di Sma Negeri 11 Makassar. Gema Kampus IISIP YAPIS Biak, 11(1), 55-62. https://doi.org/10.52049/gemakampus.v11i1.17.

Darimi, I. (2015). Peningkatan Kompetensi Pedagogik Guru PAI dalam Pembelajaran. Jurnal Mudaarrisuna, 4(2). https://doi.org/10.22373/jm.v5i2.630.

Dody, S. (2016). Peran Self Awareness dalam Memediasi Pengaruh Supervisi Akademik Pengawas dan Kemampuan Manajerial Kepala Sekolah terhadap Kompetensi Guru. Jurnal Pendidikan Ilmu Sosial, 26(1), 35-43. https://doi.org/10.2317/jpis.v26i1.2063.

Gani, H. M. U., Nur, M., Mallongi, H. S., \& Rusjdin, H. (2018). The Impacts of Competence, Work Motivation, Job Satisfaction and Organizational Commitment on Lecturers' Performance. IRA-International Journal of Management \& Social Sciences, 11(1), 17. https://doi.org/10.21013/jmss.v11.n1.p2.

Hasli, R., Sappaile, B. I., \& Pristiwaluyo, T. (2015). Pengembangan Instrumen Kompetensi Pedagogik Guru Kelas Sekolah Dasar Di Kecamatan Marioriwawo Kabupaten Soppeng. Riset Assesmen: Jurnal Penelitian Dan Evaluasi Pendidikan, 1(1), 1-7. Retrieved from. https://ojs.unm.ac.id/assesment/article/view/1773.

Indriani, A. (2015). Penerapan Pembelajaran Tematik Kurikulum 2013 oleh Guru SD/MI di Desa Klepek Kecamatan Sukosewu Kabupaten Bojonegoro Semester Gasal Tahun Ajaran 2014/2015. Jurnal VARIDIKA, 27(1), 43-49. https://doi.org/10.23917/varidika.v27i1.738.

Jatiningsih, O., Maya Mustika Kartika Sari, Habibah, S. M., Setyowati, R. N., Yani, M. T., \& Adi, A. S. (2018). Penguasaan Kompetensi Profesional Guru oleh Mahasiswa Peserta Praktik pengalaman pembelajaran. Jurnal Civics: Media Kajian Kewarganegaraan, 15(1), 170-179. https://doi.org/10.21831/jc.v15i1.17291.

Karom, D., Ruhimat, T., \& Darmawan, D. (2014). Pengaruh Kompetensi Pedagogik Guru Dalam Menerapkan Pembelajaran Kooperatif Berbantuan Media Presentasi Terhadap Hasil Belajar Peserta Didik Pada Mata Pelajaran Matematika. Edutech, 1(2). https://doi.org/10.17509/edutech.v13i2.3113.

Khofiatun, Akbar, S., \& Ramli, M. (2016). Peran Kompetensi Pedagogik Guru Dalam Pembelajaran Tematik Di Sekolah Dasar. Jurnal Pendidikan: Teori, Penelitian, Dan Pengemban, 1(5), 984 - 988. https://doi.org/10.17977/jp.v1i5.6336.

Maiza, Z., \& Nurhafizah, N. (2019). Pengembangan Keprofesian Berkelanjutan dalam Meningkatkan Profesionalisme Guru Pendidikan Anak Usia Dini. Jurnal Obsesi :Jurnal Pendidikan Anak Usia Dini, 3(2), 356-365. https://doi.org/10.31004/obsesi.v3i2.196.

Muhammad Ridwan Kalu, A. R., \& Mahpudz, H. A. (2016). Kompetensi Pedagogik Dan Profesional Guru Sekolah Dasar Yang Tersertifikasi Pada Pembelajaran Sains. Jurnal Sains Dan Teknologi Tadulako, 5(3), 85-94. Retrieved from. http://jurnal.untad.ac.id/jurnal/index.php/JSTT/article/download/6984/5621.

Nur, A. A. (2014). Meningkatkan Kompetensi Pedagogik Guru Di Sd Yayasan Mutiara Gambut. Jurnal Bahana Manajemen Pendidikan, 2(1), 65-72. https://doi.org/10.24036/bmp.v2i1.3735.

Nuralan, S. (2020). Kopetensi Pedagogik Guru Dalam Mendesain Pembelajaran Di Sd Negeri 23 Tolitoli. Jurnal Pendidikan Dasar Dan Keguruan, 5(1), 66. https://doi.org/10.47435/jpdk.v5i1.291.

Oetpah, F. (2019). Kompetensi Pedagogik Dan Profesional Guru: Kontribusi Terhadap Peningkatan Hasil Belajar Biologi. Jurnal Mangifera Edu, 4(1), 71-83. https://doi.org/10.31943/mangiferaedu. v4i1.38.

Pertiwi, P. A. I., \& Renda, N. T. (2020). Penerapan Model Pembelajaran Kooperatif Tipe Student Team Achievement Division (Stad) Berbantuan Media Konkret Untuk Meningkatkan Hasil Belajar 
Matematika. Jurnal Ilmiah Pendidikan Profesi Guru, 2(3), 216-227. https: //doi.org/10.23887/jippg.v2i3.14275.

Putri, B. M. A., Mudzanatun, \& Putri, A. D. S. (2020). Analisis Kompetensi Pedagogik Guru Dalam Pelaksanaan Keterampilan Dasar Mengajar Pada Pembelajaran Tematik. Indonesian Journal of Educational Research and Review, 3(1), 136-143. https://doi.org/10.23887/ijerr.v3i1.25183.

Riwanti, R., \& Hidyati, A. (2019). Pengembangan Modul Pembelajaran Tematik Berbasis Pendidikan Karakter Di Kelas V Sekolah Dasar. Jurnal Basicedu: Research \& Learning in Elementary Education, 3(2), 572-581. https://doi.org/10.31004/basicedu.v3i2.41.

Sakti, T. K., Hairunisya, N., \& Sujai, I. S. (2019). Pengaruh Kompetensi Pedagogik Guru dan Gaya Belajar Siswa Terhadap Prestasi Belajar Siswa Pada Mata Pelajaran IPS. JPIS Jurnal Pendidikan Ilmu Sosial, 28(1), 53-60. https://doi.org/10.17509/jpis.v28i1.12818.

Saputri, V. A., \& Purwadi, P. (2017). Upaya Meningkatkan Motorik Kasar Anak Melalui Metode Permainan Tradisional Egrang Bathok Kelapa Pada Kelompok B Di Ra Taqwal Ilah Semarang. Paudia : Jurnal Penelitian Dalam Bidang Pendidikan Anak Usia Dini, 4(1). https://doi.org/10.26877/paudia.v4i1.1654.

Sari, Y. S. (2018). Pengembangan Kompetensi Pedagogik Guru Sd Dalam Pembelajaran Tematik Integratif Kurikulum 2013 Berbasis Budaya Lokal. ENSAINS JOURNAL, 1(1), 65. https://doi.org/10.31848/ensains.v1i1.53.

Stephani, M. R. (2017). Stimulasi Kemampuan Berpikir Kritis Melalui Pembelajaran Berbasis Masalah Pada Pendidikan Jasmani. Jurnal Pendidikan Jasmani Dan Olahraga, 2(1), 16-27. https://doi.org/10.17509/jpjo.v2i1.6397.

Sukriadi, S., \& Arif, M. (2021). Model Pembelajaran Pendidikan Jasmani Adaptif Berbasis Permainan Untuk Anak Tunagrahita Ringan. Jurnal Ilmiah Sport Coaching and Education, 5(1), 12-24. https://doi.org/10.21009/JSCE.05102.

Sulfemi, W. B., \& Yuliana, D. (2019). Penerapan Model Pembelajaran Discovery Learning Meningkatkan Motivasi Dan Hasil Belajar Pendidikan Kewarganegaraan. Jurnal Rontal Keilmuan Pancasila Dan Kewarganegaraan, 5(1), 17-30. https://doi.org/10.29100/jr.v5i1.1021.

Sumiarsi, N. (2015). Analisis Kompetensi Pedagogik dan Pengembangan Pembelajaran Guru SD Negeri 041 Tarakan. Urnal Kebijakan Dan Pengembangan Pendidikan, 3(1), 99-104. https://doi.org/10.22219/jkpp.v3i1.2206.

Sutisna, D., \& Widodo, A. (2020). Peran Kompetensi Guru Sekolah Dasar Dalam Meningkatkan Efektivitas Pembelajaran Daring. Jurnal Bahan Manajemen Pendidikan, 9(2), 58-64. https://doi.org/10.24036/jbmp.v9i2.

Syarifuddin. (2020). Peningkatan Kompetensi Pedagogik Guru Kelas di SD IT Ihsanul Amal. Aksara: Jurnal Ilmu Pendidikan Nonformal, 6(2), 169-178. https://doi.org/10.37905/aksara.6.2.181-190.2020.

Triyusmidarti, N., \& Fauziyah Harahap, S. (2017). Analisis Kompetensi Guru Sekolah Dasar di Kecamatan Patumbak Kabupaten Deli Serdang. Jurnal Pendidikan Tabularasa, 14(2), 157-165. https://doi.org/10.24114/jt.v14i2.9692.

Tyagita, B. P. A., \& Iriani, A. (2018). Strategi Peningkatan Kompetensi Pedagogik Guru Untuk Meningkatkan Mutu Sekolah. Kelola: Jurnal Manajemen Pendidikan, 5(2), 165-176. https://doi.org/10.24246/j.jk.2018.v5.i2.p165-176.

Umi, R., Nopriansyah, U., \& Purnama, S. (2019). Korelasi Kepemimpinan Kepala Taman Kanak-Kanak Terhadap Kinerja Kompetensi Pedagogik dan Kompetensi Profesional Guru. Al-Athfaal: Jurnal Ilmiah Pendidikan Anak Usia Dini, 2(1). https://doi.org/10.24042/ajipaud.v2i1.4552.

Wahyuni, R., \& Berliani, T. (2018). Pelaksanaan Kompetensi Pedagogik Guru di Sekolah Dasar. Sekolah Dasar, 27(2). https://doi.org/10.17977/um009v27i22018p108.

Widyaningrum, W., Sondari, E., \& Mulyati. (2019). Meningkatkan Kompetensi Profesionalisme Guru di Abad 21 Melalui Pelatihan Pembelajaran Bahasa Inggris. DEDIKASI: Jurnal Pengabdian Masyarakat, 1(1), 35-44,.

Yulyani, Y., Kazumaretha, T., Arisanti, Y., Fitria, Y., \& Desyandri, D. (2020). Implementasi Kompetensi Pedagogik Guru Dalam Pembelajaran Tematik Di Sekolah Dasar. School Education Journal Pgsd Fip Unimed, 10(2), 184. https://doi.org/10.24114/sejpgsd.v10i2.18545. 